\title{
A NOÇão de VIDA EM HANNAH ARENDT e na Psicanálise
}

\section{The notion of life In HanNah ARendt and in Psychoanalysis}

\author{
Gabriela Gomes Costardia
}

Resumo Este artigo se propõe a analisar a noção de vida tal como ela é concebida no pensamento de Hannah Arendt e na Psicanálise de Freud e Lacan, desde onde se pretende contextualizar a ausência da noção de sexualidade na obra da autora. Para tal, lança-se mão das reflexões de Arendt sobre a passagem da vida da esfera pública para a privada na modernidade, fator determinante para a constituição do âmbito social, o que permite observar que a pensadora política fundamenta sua análise sobre a vida nas noções de natureza e produtividade. Analisa-se, então, a ideia psicanalítica de vida a partir do desenvolvimento da teoria pulsional em Freud e das contribuições de Lacan, a fim de demarcar como, nesse referencial, a vida coloca em jogo as noções de símbolo e morte. Por fim, observa-se que a sexualidade, conforme postulada pela Psicanálise, é derivada da compreensão de que a linguagem operou uma subversão irreversível na noção de natureza e que o não compartilhamento dessa perspectiva por Hannah Arendt está ligado ao seu silêncio sobre o sexual.

Palavras-chave vida; Hannah Arendt; sexualidade; Psicanálise; pulsão.

Abstract This article intends to analyze the conception of life in Hannah Arendt's thought and in Freud's and Lacan's Psychoanalysis in order to contextualize the absence of the sexuality notion in Arendt's work. We bring the political thinker's reflections about the passage of life from the private to the public sphere in modernity, a crucial factor for the constitution of the social realm, and we point out that the author bases her analysis about life in the notions of nature and productivity. Then we examine the psychoanalytical idea of life, using the Freudian drive theory and the Lacanian contributions, and we remark that, in this framework, the notions of symbol and death play a crucial role. Finally, we state that the sexuality, as it is postulated by Psychoanalysis, derives from the conception that language irreversibly subverts

a Doutoranda em Psicologia Escolar e do Desenvolvimento Humano pela Universidade de São Paulo e pesquisadora do Programa de Teoria Crítica da Universidade da California, Los Angeles, EUA. 
the notion of nature, and Hannah Arendt's silence about the sexual is connected with her divergence about this point.

Keywords life; Hannah Arendt; sexuality; Psychoanalysis; drive.

Estou convencida de que de todas as manifestações do efêmero, o corpo humano é o mais vulnerável, a única fonte de toda a alegria, todo o sofrimento e toda a verdade ${ }^{1}$. Alina Szapocznikow, 1972.

A vida corporificada tornou-se o bem supremo de nossos tempos seculares. Nem a honra, nem a excelência, nem a coragem ou o idealismo suplantariam o fim último de viver, a vida em si mesma, máximo valor e máxima experiência.

Utilizar-se-ão as reflexões de Hannah Arendt sobre a concepção de vida e o quadro referencial que essa concepção implica como chaves para adentrar na análise da autora sobre a sociedade moderna, colocando em jogo as noções de natureza e produtividade. Analisar-se-á também o conceito psicanalítico de vida, um pensamento que nasceu no seio dos impasses da sociedade moderna e que concebe a vida a partir de sua relação com o símbolo e com a morte. Desse percurso pretende-se propor um entendimento sobre o fato de que a Psicanálise tenha feito da sexualidade um ponto-chave em sua abordagem da vida e da morte, do corpo e da reprodução, enquanto Arendt tenha silenciado sobre esse tema em sua análise das mesmas questões.

\section{POLÍTICA EM HANNAH ARENDT - 0 AVESSO DA VIDA}

Hannah Arendt não se ocupa em formular uma teoria geral sobre política, mas pensa a partir de eventos. São os acontecimentos, e não as mentalidades, que para ela têm a capacidade de quebrar o automatismo dos processos sociais, instaurar o novo, colocando em cena a liberdade, o que localiza a política em um campo diretamente oposto ao da vida, já que esta responde ao que é necessário e recorrente. A autora pensa a política no seio da ação, a qual está atrelada à liberdade, à pluralidade e ao poder. "Os homens são livres - diferentemente de possuírem o dom da liberdade - no momento em que agem, nem antes nem depois; pois ser livre e agir são uma mesma coisa" (ARENDT, 2009, p. 199). Ao pensar a política como ação e localizar a liberdade nesse campo, Arendt insere esses conceitos em uma vertente positiva relativa à participação e à deliberação conjunta. Liberdade,

1 Em livre tradução. 
nesse caso, opõe-se tanto à noção filosófica que a associa à vontade livre e soberana quanto às concepções marxista e liberal, as quais pensam liberdade como consequência da justiça social, no primeiro caso, ou da igualdade de direitos, no segundo (Wellmer, 2002, p. 220). Para a autora, justiça social e igualdade de direitos são apenas precondições para a realização da liberdade que, para tomar corpo de fato, requer a interação efetiva entre os homens no âmbito da política.

Dois aspectos se destacam na teoria arendtiana da liberdade: igualdade e indeterminação. Começar-se-á aqui considerando a relação entre liberdade e igualdade. Arendt (2009, p. 158-159) recupera o pensamento aristotélico que diferencia o âmbito privado da família como lugar do cuidado com as necessidades biológicas e da incessante produção e consumo do que é necessário à manutenção da vida, do âmbito público, em que os cidadãos livres das necessidades biológicas se associam para cuidar dos negócios comuns. Nesse referencial, a questão da igualdade e da desigualdade de posições entre as pessoas é bem delimitada. O repetitivo trabalho requerido pelo funcionamento corporal não deixa nada atrás de si e está a cargo da esposa, dos filhos e escravos. O senhor é uma exceção, a ele cabe o comando dos demais, estabelecendo-se na casa uma desigualdade. Aí não há liberdade, nem do lado do que manda, nem dos que obedecem, já que a hierarquia que viabiliza o domínio predefine lugares, e as relações regem-se pela finalidade utilitária da administração da vida. Mas o senhor da casa, livre do trabalho cíclico relativo aos processos corporais, pode adentrar na cena pública, agora como cidadão, aquele que fala e age diante de seus iguais. A igualdade que se produz na pólis, portanto, é da ordem da isonomia, um artifício necessário para permitir que se passe da singularidade que é dada a cada um no nascimento à distinção que se produz entre "iguais" no espaço público; a igualdade antiga não se refere à noção moderna de que os homens são iguais porque nasceram iguais:

A isonomia garantia um tipo de igualdade, mas não porque todos os homens nascessem ou fossem criados iguais, mas, ao contrário, porque os homens eram por natureza não iguais e precisavam de uma instituição artificial, a pólis, que [...] os tornaria iguais (ARENDT, 2011, p. 58).

A singularidade é a diferença radical que marca um indivíduo por aquilo que ele recebeu em seu nascimento e que só pode ser acolhida no âmbito privado, já a distinção se produz em meio à pluralidade de iguais, que se diferenciam por falar e agir em um espaço de aparência. Ser igual no âmbito público implica que não haja imposição de ideias por força da hierarquia ou da violência, mas que seja a persu- 
asão o meio pelo qual os cidadãos deliberam sobre os assuntos de interesse comum. Nesse sentido, não há liberdade nas relações em que a hierarquia do âmbito privado se impõe, tais como: aluno e professor; filho e pai; escravo e senhor; empregado e chefe; paciente e médico; fiel e pastor. A igualdade é condição para que a fala e a ação circulem entre os homens e não se restrinjam a interações com destinos e efeitos predefinidos por relações hierárquicas, mantendo sua capacidade de gerar resultados inesperados e colocando em jogo uma noção de liberdade que quebra em ato as cadeias do habitual. Dessa forma, tem-se que a liberdade dá testemunho da indeterminação que habita o cerne dos assuntos humanos quando os homens interagem em condições de igualdade política.

Vê-se que, para Arendt, a liberdade não é uma experiência referente ao mundo interior do indivíduo, em que ele poderia superar as amarras sociais, mas sim o fato de que realizar uma ação entre indivíduos no plural implica não ser possível determinar o curso dos eventos e suas consequências, já que o impulso que desencadeia a ação terá que circular pela rede de relações, intenções, interesses, disposições e opiniões formada pelos indivíduos que agem em conjunto. Nesse sentido, coloca-se a análise da autora sobre as palavras gregas e latinas utilizadas para designar a ação, as quais se dividem em dois momentos que expressavam o caráter de interdependência entre o iniciador e os realizadores da ação.

Aos dois termos gregos archein ("começar", "liderar" e, finamente, "governar") e pattein ("atravessar", "realizar" e "acabar") correspondem os dois verbos latinos agere ("pôr em movimento", "liderar") e gerere (cujo significador original é “conduzir”) (ARENDT, 2010a, p. 236).

O impulso inicial para criar algo, a idealização de uma nova realidade, o poder de iniciativa e a tomada de responsabilidade pelo início estão a cargo de alguém que lidera, que põe em movimento, mas a realização da ação depende de que se consiga implicar outros, reunir pessoas que tomem parte no curso dos eventos, os quais, por sua vez, dependem de quem iniciou a ação para ter uma oportunidade de agir. Daí o caráter dividido do empreendimento humano, a impossibilidade de saber exatamente aonde se vai chegar quando se age na esfera pública. O fato é que, nas línguas modernas, essa diferença se esvaiu, e as palavras passaram a designar dois sentidos diversos. A ação em si ficou sendo referida apenas pelos termos que designavam seu curso, e aqueles que designavam seu início passaram a indicar um tipo de liderança que não implica a interdependência do suporte de outros, mas uma relação de obediência. O iniciador da ação antigo e o governante atual estão 
em posições diversas, na medida em que o primeiro precisava da ajuda de outros enquanto o segundo impõe suas ordens a quem deve cumpri-las e reivindica para si o sucesso do feito de muitos.

Por meio dessa reivindicação, o governante monopoliza, por assim dizer, a força daqueles sem cujo auxílio ele jamais teria sido capaz de realizar coisa alguma. E assim surge a ilusão de força extraordinária e, com ela, a falácia do homem forte que é poderoso por estar só (ARENDT, 2010a, p. 237).

Entende-se que essa mudança observada nas línguas modernas dá testemunho de uma tentativa de restabelecer a unidade da ação e recusar seu caráter indeterminado e contingente, defender-se da liberdade, a qual só pode ser suportada atualmente como um atributo do mundo interior do indivíduo, no sentido de um espaço fora do alcance das restrições sociais, ou seja, a liberdade como soberania da vontade. Cabe pontuar que, contrariamente a essa posição, a Psicanálise, sendo uma práxis nascida na sociedade moderna, opera a partir de uma experiência de indeterminação que tem lugar fora da cena pública, mas que não se restringe ao solipsismo de uma liberdade privada derivada da noção de soberania.

Como inspira sua concepção de ação política no modelo ateniense, fundado sobre uma exclusão contrária aos valores modernos, Hannah Arendt é por vezes tida como uma pensadora nostálgica. É importante observar, no entanto, que ela reconheceu, em acontecimentos de seu tempo (e não de um tempo perdido) - como o conselho revolucionário que ficou encarregado de responder à tirania russa durante a Revolução Húngara, em 1956, ou os movimentos de desobediência civil que obtiveram conquistas quanto aos direitos civis e protestaram contra a guerra do Vietnã, nos Estados Unidos, na década de 1960 - a possibilidade de a associação dos cidadãos na esfera pública quebrar o automatismo dos processos sociais, provocando mudanças na cena política em curso. Foi isso que Arendt (1958) reconheceu na revolução popular ocorrida na Hungria, ocupada pelos russos, em 1956, quando uma manifestação estudantil em nome da liberdade mobilizou a população mais ampla, que, diante da tentativa de dispersão da manifestação pela polícia, se revoltou. $\mathrm{O}$ exército, chamado para ajudar a polícia, mudou de lado e armou o grupo revoltoso, sendo a ditadura destituída em poucos dias: "Foi como se a ideologia, de qualquer tonalidade ou marca, tivesse se dizimado da existência e da memória no momento em que as pessoas, intelectuais e trabalhadores, comunistas e não comunistas, 
encontraram-se juntos nas ruas lutando por liberdade" (ARENDT, 2010c, p. 27) 2 . O grupo que empreendeu a resistência não se filiou por pertencer a uma classe específica, nem em nome de um ideal doutrinário; as pessoas não foram guiadas por uma liderança carismática, nem se renderam a uma preparação calculada ou a uma necessidade decisiva, mas o fato é que o curso dos acontecimentos sofreu do inesperado, de uma associação popular que não respondia aos moldes da resistência tradicional, fazendo entrar em cena a liberdade.

Assim, a crítica arendtiana à época moderna fundamenta-se na restrição do espaço público capaz de acolher a deliberação de homens iguais como modo próprio de operação, a qual colocaria em cena a liberdade que emerge da ação entre homens no plural. Arendt fundamenta sua análise sobre a destruição do espaço público na invasão dele pelas necessidades biológicas que outrora estavam a cargo da esfera privada. Para a autora, isso implica a ruína da esfera pública enquanto lugar da liberdade, já que a vida biológica está sob o regime da necessidade, bem como houve a substituição do âmbito privado pela noção de intimidade, já que o primeiro perdeu sua prerrogativa de guardar da luz as atividades ligadas à vida, e tudo o que restou e é privado foi o espaço íntimo do corpo e do mundo subjetivo. Em suma, os homens modernos menos agem do que se comportam, o que os torna bastante familiarizados com os hábitos, os condicionamentos, a instrumentalização e as estatísticas, e (quase) estranhos à experiência da liberdade.

\section{A VIDA VAI AO PÚBLICO}

Como se tratou anteriormente, o modelo de organização social da antiga Atenas dividia nitidamente a administração da vida, regida pela necessidade e relegada ao âmbito privado, da ação política, regida pela liberdade e realizada no âmbito público. Esse modo de organização está atrelado a uma concepção de homem em vigor na época, expresso do seguinte modo: "Tudo o que os homens tinham em comum com as outras formas de vida animal não era considerado humano" (ARENDT, 2010a, p. 104). Ou seja, não se pode reconhecer a especificidade do homem no registro da biologia, nem nas atividades que se dedicam a prover as demandas do corpo, já que esse âmbito é regido pela coação das urgências orgânicas. As necessidades humanas são aqui naturalizadas, e os homens são diferenciados dos animais pela capacidade de agir e falar em um espaço de liberdade ${ }^{3}$. Nesse sentido, os escravos

2 Em livre tradução. Consultar: <http://www.jstor.org/stable/2127387>.

3 Para uma crítica, de perspectiva marxiana, ao antagonismo entre as noções de necessidade e liberdade na obra de Arendt ver Gaspar (2011, p. 64). 
e as mulheres não são humanos: animal laborans é sua designação mais propícia, pois se restringem a realizar as atividades que visam à necessidade, e sua fala está referida à autoridade do senhor, não havendo possibilidade de que algo novo se instaure por sua fala e ação (AREndT, 2010a, p. 104).

Em $A$ condição humana, Hannah Arendt define como, a partir da época moderna, as atividades escondidas na privatividade do lar tomaram a cena pública, ficando a política propriamente dita relegada à finalidade de servir às necessidades de sobrevivência; a política tornou-se uma função da vida, dedicando-se primordialmente a administrar questões econômicas. "A sociedade é a forma na qual o fato da dependência mútua em prol da vida, e de nada mais, adquire importância pública, e na qual se permite que as atividades relacionadas com a mera sobrevivência apareçam em público" (ARENDT, 2010a, p. 56). Um dos importantes impactos da destruição dos âmbitos privado e público pela emergência do social é a dificuldade de coexistência da diferença; a sociedade é o espaço do mesmo, a grande família, onde todos se guiam por um único interesse, e não por opiniões individuais; é o lugar da massa. Se a igualdade na esfera privada é relativa à biologia que reúne a todos como membros da espécie humana e, na esfera pública, ela apresenta-se como isonomia política, que garante a todos o direito de se expressar igualmente, na esfera social a presença da igualdade ocorre como demanda de conformidade, de homogeneidade identitária, empuxo à normalização e ao estabelecimento de padrões. "A humanidade socializada é aquele estado da humanidade no qual impera somente um interesse, e o sujeito desse interesse são as classes ou o gênero humano, mas não o homem nem os homens" (ARENDT, 2010a, p. 401). Em suma, quando absorvido pela lógica social, o espaço público não permite a aparência dos homens enquanto indivíduos, condição necessária à ação política, mas considera-os enquanto integrantes do gênero humano, entidade globalizante e abstrata que deve ser administrada por uma racionalidade predeterminada.

O que a autora ressalta é que a transposição das atividades do privado para o público destrói ambos os espaços em suas lógicas próprias, na medida em que uma esfera necessita da outra como ponto de referência. Se a esfera pública é o foro privilegiado da ação humana, por outro lado, ela só pode funcionar dessa forma porque não está encarregada de acolher a totalidade da experiência humana. Nem todas as atividades se beneficiam da exposição à luz do público, é preciso lembrar que a distinção que tem lugar na cena política se fundamenta em assuntos de relevância para o mundo comum e tem como critério de pertencimento a grandeza. Na política, coloca-se a vida natural em risco em nome das grandes ações e persegue-se a imortalidade por via da lembrança que a história pode guardar 
dos feitos elevados; a morte que contraria o ciclo natural da vida, a morte heroica, é frequentemente meio de imortalidade no registro da política. Assim, que lugar senão o privado poderia acolher a idiossincrasia, a singularidade, o irrelevante, a preocupação com a vida? Veja como Arendt demarca claramente essa separação e como ela faz sua crítica operar: "Dada sua inerente não mundanidade [worldlessness], o amor só pode ser falsificado e pervertido quando utilizado para fins políticos, como a transformação ou a salvação do mundo" (ARENDT, 2010a, p. 63). A autora entende que a esfera privada é o habitat legítimo do amor. Sendo esse um afeto que estabelece e regula laços interpessoais baseados em preferências idiossincráticas, inescrutáveis por vezes, o amor é um antídoto para a capacidade de julgamento, faculdade política por excelência segundo Arendt. Ao acusar a perversão deste afeto quando utilizado para fins políticos, a pensadora condena a dominação de líderes carismáticos sobre as massas que, tomadas pelo amor/ adoração, têm perturbada sua capacidade de julgar, ficando privadas de agir e deliberar em conjunto. Fica claro, dessa forma, como para a autora o que é pertinente ao âmbito privado não o é ao público, cada esfera é apta a acolher um nível diverso da experiência humana e ambas se limitam entre si.

Ao pensar sobre o borramento desses limites entre o privado e o público, Arendt destaca para um novo modo de funcionamento das questões ligadas à vida. Ela afirma que, ao dependerem um do outro para funcionar em sua especificidade, público e privado também se limitam. Assim, com a transposição da lógica da necessidade para o público, a vida perdeu o equilíbrio que lhe era conferido pela experiência de perecimento característica da esfera privada.

Quando a atividade do trabalho foi liberada das restrições que lhe eram impostas por seu banimento, o domínio privado, [...] foi como se o elemento de crescimento inerente a toda a vida orgânica houvesse completamente superado e prevalecido sobre os processos de perecimento por meio dos quais a vida orgânica é controlada e equilibrada no lar da natureza (ARENDT, 2010a, p. 57).

A partir dessa noção de perda de limites, Arendt faz uma análise da vida em termos de positividade e produtividade, o que se converte em capacidade destrutiva, quando alinhado ao excesso. A vida se libera das amarras da casa e adentra à luz do público, em toda a sua capacidade de fertilidade, produção, abundância, crescimento e proliferação. E, nessa vertente, a autora é capaz de abordar o apelo que surge do referencial da vida à cultura moderna e à sedução que esse referencial exerce no mundo atual. 
A positividade, processualidade, o caráter expressivo e expansivo da vida na esfera pública não é de forma alguma um argumento contra sua responsabilidade no processo restritivo, conservativo, reificante e thanatopolítico, o qual ela provoca e aumenta [...] (BLENCOWE, 2010, p. 121)4.

Arendt enfatiza que esse conjunto de noções ligadas à vida pode destruir o mundo. Para abordar esse ponto de sua análise, far-se-ão algumas considerações sobre a ideia de processo. Processo é uma noção que está ligada, primeiramente, ao âmbito da vida. Não se encontra na esfera das necessidades corporais uma relação propriamente de causa e efeito, mas sim a repetição de ciclos que acontecem em uma infindável relação de produção e consumo. A atividade responsável por produzir aquilo que será consumido pelo processo vital é o trabalho; ele não deixa nada atrás de si, pois seus produtos são integrados quase imediatamente à vida orgânica e perecem, caso não o sejam. Portanto, ainda que seja essencial à sobrevivência humana, o trabalho não acrescenta nada ao artifício humano, ele é incapaz de constituir o mundo, pois não produz nada em condições de durar (ARENDT, 2010a, p. 107).

O mundo é feito de objetos que, por permanecerem por certo tempo à disposição dos homens, oferecem uma espécie de identidade, objetividade e estabilidade a eles. As obras de arte são os melhores exemplos de objetos mundanos, segundo a autora, na medida em que podem alcançar uma permanência que atravessa gerações, integrando-se à tradição e constituindo o mundo comum. A atividade que constrói o mundo é a fabricação; sem dúvida ela violenta a natureza, mas seu produto não será consumido pelo processo vital imediatamente, senão constituirá um artifício que pretende ser mais duradouro do que o ciclo de vida individual. A questão do processo também aparece na fabricação, mas ele não é um fim em si mesmo, ele se interrompe com a produção do objeto, contrariamente ao trabalho, que quase não distingue processo e produto. A fabricação é uma atividade que se limita pela relação de utilidade, ela opera pela lógica dos meios e fins, oferecendo resistência à relação produção-consumo pela via do objeto. O produto da fabricação é para ser usado, não consumido, seu desgaste é incidental, e não inerente. Uma das belas reflexões de Arendt, nesse sentido, é sobre a etimologia latina da palavra objeto. Segundo ela, obicere traz implícita a ideia de "algo que é lançado ou colocado contra” (ARENDT, 2010a, p. 137). Portanto, o objeto da fabricação é aquilo que gera estabilidade e identidade aos homens, mas também é o que resiste à devoração, que

4 Em livre tradução. Consultar: <http://hhs.sagepub.com/content/23/5/113>. 
contraria o imperativo da produção desenfreada, que limita o movimento da vida que se autoalimentar, fazendo com que tudo o mais pereça. Uma das críticas da pensadora ao sistema produtivo moderno, o qual tomou como fim último a administração econômica em detrimento da liberdade, é que a fabricação foi dividida em tantas subpartes e seus objetos pretendem ser tão perecíveis que ela se transformou em nada mais nada menos do que trabalho.

O fato é que vida e mundo têm lógicas incompatíveis: enquanto a primeira está implicada em um processo ininterrupto de produção e consumo, o segundo vela pelas noções de estabilidade e duração. Enquanto habitavam esferas separadas, nenhum ameaçava o outro e ambos se limitavam entre si, mas, com a emancipação da vida do âmbito privado, o conflito entre suas lógicas se coloca. E, com a crescente expansão da vida, Arendt chama a atenção para a possibilidade de destruição do mundo. A instauração desse paradigma subverte os instrumentos e as ideologias que visam à destruição, já que estes precisam aderir à noção produtiva para se legitimar. Em relação à eliminação da vida, dá-se o paradoxo de uma morte que se realiza em nome da potencialização do vivo. É o que se vê, por exemplo, na ideologia do racismo nazista que eliminaria as raças inferiores em nome de criar uma raça superior, o que não responde à lógica da guerra, que pretende destruir inimigos políticos ${ }^{5}$.

O que chama a atenção é que, ao trazer para o centro de sua crítica da sociedade moderna a noção de vida, Hannah Arendt jamais menciona a sexualidade em suas reflexões; tudo o que se refere ao corpo fica relegado à intimidade e não fará parte de suas análises políticas. Encontra-se, no entanto, uma menção sobre a sexualidade, quando a autora diferencia as faculdades do espírito das paixões da alma, o que deixa claro seu entendimento da sexualidade e do corpo enquanto dados naturais. Arendt (2010b) esclarece que as faculdades do espírito - pensar, querer e julgar - não encontram equivalência em uma experiência somática; ao contrário das emoções, tais como a mágoa, a alegria, o ódio, a inveja, etc. O corpo sofre alterações ao experimentar os afetos, e aí reside sua natureza animal, geradora de respostas comuns entre os membros da espécie humana. O impulso sexual responderia, então, à necessidade de manutenção da vida, tal como o medo levaria à busca de proteção diante do perigo da morte. E, enquanto o impulso sexual se

5 Veja como essa análise converge com a de Foucault: “Tirar a vida, o imperativo de morte, só é admissível, no sistema do biopoder, se tende não à vitória sobre os adversários políticos, mas à eliminação do perigo biológico e ao fortalecimento, diretamente ligado a essa eliminação, da própria espécie ou da raça. A raça, o racismo, é a condição de aceitabilidade de tirar a vida numa sociedade de normalização" (FouCAult, 1999, p. 306). 
refere a sensações corporais repetitivas e monótonas, apenas sua manifestação no mundo das aparências, o amor aparece de forma múltipla e rica. A partir desse ponto de vista, a autora entende que a Psicologia e a Psicanálise, estando aptas a navegar apenas no âmbito dos humores internos, não encontram achados interessantes nem significativos, e o que se descobriu com a moderna busca em iluminar as profundezas da alma foi um tesouro de perversidades, a fealdade que não faz jus à multifacetada expressão humana testemunhada no âmbito público (ARENDT, 2010b, p. 51).

Se o fundamento psíquico interno de nossa aparência individual não fosse sempre o mesmo, não poderia haver ciência psicológica, que, enquanto ciência, se apoiasse em um "por dentro todos nos parecemos" de ordem psíquica, assim como a fisiologia e a medicina apoiam-se na "mesmidade" de nossos órgãos internos (ARENDT, 2010b, p. 50).

Fica clara, assim, a impossibilidade de Arendt fazer entrar para a política um corpo vivo, que sofre, deleita-se, afeta-se e se satisfaz em seu contato com o outro; tem a ver com a naturalização que ela imputa a esse, tal como à vida, e daí sua ausência de reflexão sobre a sexualidade. Nessa linha, Kristeva aponta que a pensadora política reduz sua análise sobre a violência ao não reconhecer o corpo como lócus da individualidade.

Devemos lembrar, todavia, que a recusa a contemplar a singularidade do corpo e do psiquismo é o que levou Arendt a recusar o reconhecimento do papel desempenhado pelo sadomasoquismo na experiência da violência, particularmente na violência política que acompanha o totalitarismo bem como os movimentos da moderna Esquerda (KrISTEva, 2001, p. 180).

Para Arendt, o corpo é o organismo, incomunicável e privativo. Ela o localiza na esfera da intimidade, aquela que substituiu a esfera privada quando da emergência do social na modernidade, sendo o que restou da noção de propriedade privada. Nesse novo referencial, a demanda de felicidade ofuscou a de liberdade, que era própria ao público. A mundanidade da política e as recompensas e os castigos da vida pós-morte cederam lugar para a busca da satisfação corporal. É na urgência de ser feliz e desfrutar do corpo, no limite da dor e do prazer, que se movem os homens dos tempos atuais. 
Sob esse aspecto, o corpo realmente passa a ser a quintessência de toda a propriedade, uma vez que é a única coisa que não se pode compartilhar, ainda que se desejasse. Nada, de fato, é menos comum e menos comunicável - e, portanto, mais seguramente protegido contra a visibilidade e a audibilidade do domínio público - o que se passa dentro do nosso corpo, seus prazeres e suas dores, seu trabalho e seu consumo (ARENDT, 2010a, p. 138-139).

Assim, há dois aspectos a ressaltar sobre a concepção arendtiana de vida: a autora adere ao referencial aristotélico ao tomar a vida como um dado da natureza relativo às necessidades do corpo, à biologia da espécie humana, e acrescenta a isso um aspecto produtivo ao reconhecê-la fora dos limites da vida privada, enquanto fundamento constitutivo do social na modernidade. Tendo isso em mente, passa-se a analisar uma concepção de vida que nasceu no seio da sociedade moderna, por uma teoria que se construiu a partir da escuta clínica dos sujeitos desse tempo.

\section{A VIDA PARA A PSICANÁLISE}

Que é a vida para a Psicanálise? Parte-se do seguinte ponto: a Psicanálise pensou a vida não em si mesma, mas a partir das forças que a animam. Lacan, em seu segundo seminário, diz que "[a] biologia freudiana não tem nada a ver com biologia. Trata-se de uma manipulação de símbolos no intuito de resolver questões energéticas [...]" (LACAN, 1985, p. 100). A energética freudiana leva à noção de que a matéria orgânica é animada, e o que a anima recebe o nome de pulsão; em outras palavras, a energética freudiana refere-se ao corpo pulsional.

Freud trabalha o nascimento da pulsão a partir de uma noção homeostática de aparelho psíquico ${ }^{6}$; ele parte do princípio de que o organismo recebe estímulos tanto internos quanto externos, os quais "perturbam" sua homeostase, portanto, requerem algum tipo de tratamento, a fim de serem eliminados. A evitação tem certa eficácia diante dos estímulos externos - por exemplo, fechar os olhos quando se está diante de uma intensa luz -, mas não é possível evitar aquilo que estimula do interior, como a fome. Assim, Freud entende que os estímulos permanecem certo tempo no organismo e causam um aparelho psíquico, ou melhor, eles deixam traços, desde sua entrada até sua saída, marcam uma espécie de superfície que ele entendeu como parte do cérebro e, assim, perdem certa quantidade de energia. Essas marcas constituem facilitadores, caminhos pelos quais novos estímulos passarão, isto é,

6 Sobre a formação do aparelho psíquico, ver seção B do capítulo VII de Interpretação dos sonhos, do autor. 
as marcas serão sempre reativadas por novos estímulos e tornar-se-ão um modo de ligação usual das cargas energéticas, contribuindo para a manutenção de um nível de excitação relativamente confortável no sistema. Os traços primeiros são uma espécie de protótipo de um sistema simbólico, e Freud postula que a pulsão se instaura na passagem do estímulo por essas marcas do aparelho psíquico, referidas ao símbolo e à linguagem, ou seja, a pulsão está no limite entre o orgânico e o psíquico. Isso quer dizer que o estímulo origina-se no organismo, mas seu destino será definido pela ligação que ele estabelece com a linguagem, já que a experiência analítica demonstrou que as representações estão sujeitas à censura e, portanto, disfarçam-se, combinam-se, invertem-se, determinando as vicissitudes da energia que afetou o aparelho psíquico (FrEUd, 2006, p. 152).

Far-se-á um breve apanhado do desenvolvimento da teoria das pulsões para chegar a observar de que forma ela tornou-se o principal campo de reflexão sobre a vida na psicanálise. A primeira tentativa de classificação das pulsões feita por Freud partiu da diferença comumente reconhecida entre fome e amor, quando ele postulou que há pulsões que se dedicam a preservar o organismo, as pulsões do ego, e outras que são responsáveis pelo prazer do órgão, as pulsões sexuais. Essa divisão está fundamentada na noção de que a satisfação das necessidades corporais implica uma redução da tensão, o que gera uma experiência de prazer, o qual foi reconhecido por Freud como possuindo a qualidade do sexual, já que ele observou tratar-se de uma experiência relativa ao prazer genital, apesar de ter origem em outros órgãos corporais, as pulsões parciais. A terminologia pulsão sexual foi enunciada pela primeira vez em Três ensaios sobre a teoria da sexualidade; e até aí Freud opunha, de forma mais ampla, o ego à sexualidade e utilizava para designar o que posteriormente conceituou como pulsão sexual as expressões: excitação, ideias afetivas, estímulos endógenos, entre outros. Já a conceituação das pulsões do ego foi feita pela primeira vez em $A$ concepção psicanalítica da perturbação psicogênica da visão, em que elas foram identificadas explicitamente como pulsões de autoconservação. Nesse momento, o fundador da Psicanálise sediou no organismo o conflito entre essas duas correntes pulsionais e colocou as pulsões sexuais do lado daquilo que visa ao prazer, podendo, inclusive, ameaçar o funcionamento dos órgãos do corpo. Assim, o que é prazer para as pulsões sexuais é ameaça para as pulsões do ego, e isso gera a defesa pelo recalcamento. O problema é que a pulsão sexual não é eliminada com o recalque; pelo contrário, ela continua atuando de forma poderosa. Freud explicita esse mecanismo valendo-se da questão do olhar: o prazer sexual ligado ao olhar, quando excessivo, atrai a ação censora das pulsões do ego, que pretendem evitar que a função orgânica 
seja perturbada; mas, estabelecido o conflito entre os dois conjuntos pulsionais, a perturbação orgânica da visão aumenta, o que se vê ocorrer na cegueira histérica (FREUd, 1976). O que se pode já demarcar antes de avançar na discussão sobre as pulsões é que o corpo para a Psicanálise não é um dado natural, contrariamente à posição de Hannah Arendt. Freud articulou sua teoria a partir do tratamento de pessoas que tinham seu corpo afetado pela linguagem, os histéricos, e, a partir dessa clínica, ele formulou sua metapsicologia, sendo as teorias pulsionais um esforço de pensar sobre o corpo que é recortado e impresso pelo símbolo. É desse encontro do orgânico com a linguagem que nasce o sexual, daí advém a pulsão. A ideia de um corpo natural só é pensável na Psicanálise a partir da inserção na linguagem, de onde se pode imaginá-lo como um estado originário perdido, isto é, não há a coexistência do âmbito da natureza e da cultura, mas a noção de natureza é propriamente uma produção que se faz a partir da cultura. Por exemplo, pensa-se que a retirada da lei relegaria as pessoas à selvageria da natureza, que povos indígenas vivem em harmonia com a natureza, que os animais são felizes porque estão em continuidade com o ambiente natural, enfim, tem-se representações da natureza que dizem da inserção no mundo simbólico e não se tem de fato acesso à natureza.

A teoria das pulsões confere novo passo em À guisa de introdução ao narcisismo. Freud não invalida o antigo par pulsional "pulsões sexuais $x$ pulsões do ego", mas, a partir da análise de alguns fenômenos, postula outra classificação para a pulsão, conforme ela se ligue ao ego ou aos objetos externos. Ele se fundamenta na definição de narcisismo de Paul Nacke, a qual denota "a atitude de uma pessoa que trata seu próprio corpo da mesma forma pela qual o corpo de um objeto sexual é comumente tratado" (FREUD, 2004, p. 97), mas desliga esse conceito da perversão, conforme sua origem, e define-o como "o complemento libidinal do egoísmo do instinto de autopreservação” (FREUD, 2004, p. 97). Nessa nova conceituação, a ideia de que no ego atuam as pulsões de autoconservação e de que as pulsões sexuais ligam o sujeito ao objeto fica relativizada, pois também há um investimento sexual no ego. O psicanalista vienense chega a discutir a validade de manter a separação entre esses dois tipos de pulsão, mas opta por reafirmá-la, com o intuito de fazer valer a noção de conflito pulsional que ele observava na clínica.

Em Além do princípio do prazer, Freud formulou a última versão de sua teoria pulsional. O princípio do prazer foi o princípio homeostático que teve papel regulador nas teorias pulsionais de até então. Ele implica que o aparelho psíquico funcione com níveis constantes e reduzidos de tensão, ou seja, quando o aparelho experimenta algum excesso de excitação, ele coloca em ação mecanismos 
para reduzi-lo, diminuindo o desprazer e produzindo o prazer. Contudo, Freud se depara com um fenômeno clínico no qual não reconhece a atuação do princípio do prazer: a repetição na transferência de situações difíceis e emoções penosas. $O$ fracasso, a rejeição, a confusão, o sentimento de inferioridade, nada disso produziu prazer no passado e nem tem chance de produzi-lo em sua repetição atual. Essas experiências seriam muito menos desprazerosas se retornassem a partir de sonhos ou lembranças, e sua repetição em ato não está referida ao princípio do prazer. A transferência coloca a repetição no âmbito de uma compulsão, a qual o paciente não pode evitar, apesar do sofrimento que lhe causa.

A partir da noção de compulsão à repetição, Freud passa a analisar a neurose traumática. A série prazer-desprazer está ligada a um funcionamento do aparelho psíquico em que certos mecanismos de defesa mantêm as excitações que o invadem sob algum tipo de controle. Nos casos em que há uma invasão do aparelho por grandes quantidades de estímulos - como nos traumas -, o princípio do prazer fica posto de lado. Nas neuroses traumáticas houve um rompimento do escudo protetor que maneja a entrada e a saída dos estímulos do aparelho psíquico e uma falha na preparação para o medo, que é a última linha de defesa desse escudo. Os sonhos desses pacientes repetem a situação do trauma em que a neurose se instaurou, mas com um objetivo que não é regido pelo princípio do prazer, como acontece na realização alucinatória dos desejos; senão, eles têm a intenção de dominar retrospectivamente o estímulo, revivendo o medo, cuja omissão constituiu a causa da neurose traumática. Esse objetivo não é contraditório ao princípio do prazer, mas independente dele, e Freud levanta a hipótese de que seja mais primitivo do que este último. $\mathrm{O}$ psicanalista passa, então, da análise de fenômenos pontuais à postulação de um princípio do funcionamento mental, já que, em toda a vida pulsional, operaria um mecanismo análogo ao descrito a partir das neuroses traumáticas. As pulsões ${ }^{7}$ respondem ao processo primário, no qual as catexias são livremente móveis; os extratos mentais mais elevados precisam sujeitar essas excitações, para que elas respondam ao princípio do prazer, e esse assujeitamento é independente do princípio do prazer e até o despreza. Assim, tudo o que não for inserido nesse princípio apresenta um caráter pulsional acentuado, levando à compulsão à repetição.

A partir dessa postulação, Freud estabelece uma ligação entre o pulsional e a compulsão à repetição, dizendo que "uma pulsão seria, portanto, uma força

7 Nesse texto, parece que o sentido dado por Freud à palavra pulsão refere-se apenas ao seu elemento quantitativo. 
impelente [Drang] interna ao organismo vivo que visa a restabelecer um estado anterior, o qual o ser vivo precisou abandonar devido à influência de forças perturbadoras externas" (FREUD, 2006b, p. 160). Quando se detém sobre o que significa a tendência de retorno, o referido autor encontra-se com a questão da morte e, então, postula um mito: a substância inanimada foi animada por determinada força, e a tensão que se produziu gerou uma tendência de retorno ao estado anterior. A morte, porém, não é perseguida a qualquer preço, há um curso a ser seguido para alcançá-la, e as pulsões de autoconservação se encarregam de fazer valer esse ciclo até que a morte se estabeleça: "o organismo deseja morrer apenas do seu próprio modo" (FREUd, 2006, p. 57). Nesse mito da tendência ao retorno, Freud, apoiado na teoria biológica de Weissmann, reconhece uma exceção quanto às células germinais, as quais não têm como objetivo final a morte. Elas se separam do organismo, fundem-se com outras células similares e geram uma nova vida, assegurando a "imortalidade" da substância viva - esse mecanismo de ligação de elementos em unidades maiores é o modo de atuação das pulsões que promovem a vida, às quais o autor recorreu com a mitologia grega para chamar de Eros. Foi a característica libidinal do investimento egoico postulado já no narcisismo que possibilitou ao psicanalista vienense estender a libido para as células individuais e tomá-las como uma expressão de Eros, o qual também possui uma parte voltada aos objetos, estabelecendo, dessa forma, o par pulsão de vida versus pulsão de morte. A partir desse momento, pode-se dizer que a vida para Freud é uma pulsão, a qual se opõe (e se conjuga) a outra pulsão, de princípio contrário ao seu: a pulsão de morte.

Passa-se a seguir a explorar os desenvolvimentos de Lacan sobre o tema. Em seu segundo seminário, o autor comenta o texto Além do princípio do prazer, com base na noção de máquina, enquanto encarnação da mais radical atividade simbólica no homem. Ele diz que a divisão que Descartes fez entre o corpo e a alma, deixando o primeiro do lado da máquina, não pode ser desfeita.

Está máquina (relógio) [...]. Não é, pura e simplesmente, o contrário do vivente, o simulacro do vivente. [...] a máquina está ligada a funções radicalmente humanas. Não é um simples artifício, como poderíamos dizê-lo das cadeiras, das mesas, e dos outros objetos mais ou menos simbólicos em meio aos quais moramos sem nos darmos conta de que são nosso próprio retrato (LACAN, 1985, p. 99).

O psicanalista francês diz que o homem tem um corpo, à oposição dos animais que são um corpo, e esse corpo, enquanto animado por uma energética, responde 
ao princípio do prazer. O que perturba esse princípio é o símbolo; é ele que faz o corpo não tornar a se equilibrar e repetir o sofrimento compulsivamente. A linguagem desregula o corpo biológico e aí está a pulsão de morte. Para Lacan, a pulsão de vida está do lado da morte natural, que se experimenta ao cumprir-se o ciclo vital, e a pulsão de morte diz da morte enquanto expressão de que o homem não vai apenas ao encontro de seu bem, vai também ao encontro do que está além do princípio do prazer. Repete-se, no entanto, que não há corpo humano que não esteja submetido ao simbólico, o que leva à noção de que as pulsões de vida e de morte sempre se manifestam amalgamadas. Esse é um dos pontos que levam Lacan a encontrar monismo onde Freud queria dualismo, quando ele chega a dizer: "Toda pulsão é virtualmente pulsão de morte" (LACAN, 1998, p. 863), ou seja, o corpo sempre está atravessado pelo símbolo e deseja escolher sua morte para além da natureza. "A exceção, no reino da vida, são os corpos habitados pela língua, que verdadeiramente maculam o animado, os corpos da espécie humana" (Miller, 2004, p. 45).

Para a Psicanálise, a vida e a morte, tal como experienciadas no âmbito humano, são fenômenos regulados pelo símbolo. O símbolo funciona de diferentes modos nessa relação entre vida e morte: ele, o qual perturba o equilíbrio do corpo vivo e o leva à morte, antecipa a morte para pô-la em meio à vida humana e imortaliza o homem porque transmite seus (de)feitos aos que o sucedem. Ao contrário do animal, um homem morre, já que ele não é apenas um membro da espécie humana, mas um ser individualizado pelo símbolo. Os animais, por sua vez, já nascem mortos enquanto indivíduos e, ao mesmo tempo, são imortais por sua condição natural de membros de uma espécie. "Se o conceito de espécie é fundado, se a história natural existe, é que não há somente cavalos, mas o cavalo" (LACAN, 2009, p. 164, grifo do autor) ${ }^{8}$.

Além de pensar a vida em termos da incidência do símbolo na energética do corpo, Lacan também a associa ao contexto do corpo vivo do qual se goza. "[...] nós não sabemos o que é estar vivo, senão apenas isto, que um corpo, isso se goza" (LACAN, 2008, p. 29). O vivo, nesse sentido, é o que não está afetado pelo símbolo, já que este mata a Coisa, fazendo-a presente na ausência; o que se subtrai ao símbolo vive e goza. O gozo é a satisfação paradoxal, que não responde ao princípio do prazer, e da qual nada se sabe. Ainda que o gozo advenha do corpo vivo, ele não

8 Essa passagem de Lacan ressoa, embora em contexto oposto, à celebre passagem arendtiana: "A ação, única atividade que ocorre diretamente entre os homens, sem a mediação das coisas ou da matéria, corresponde à condição da pluralidade, ao fato de que os homens, e não o Homem, vivem na Terra e habitam o mundo" (ARENDT, 2010a, p. 8). 
é propriamente sujeito à pulsão de vida, ele pode estar do lado da morte. É nesse lugar, o do gozo, que se vê surgir a ligação entre a pulsão e o superego. O superego, na cultura atual, é mais uma injunção de gozo do que uma restrição a ele. Ele não se dedica a adaptar o indivíduo aos moldes da vida, moderar suas demandas de satisfação, inserir o contrapeso da realidade na corrida em busca da felicidade, mas, antes, persegue uma satisfação que é totalmente desadaptada, aparentada com a morte. É sua voz que repete: "Goza! Sempre e mais, sê feliz, tem sucesso, vence na vida, consome tudo, desfruta do corpo... Vive!”.

Assim, pode-se formular um ponto que oriente a reflexão sobre a vida no campo psicanalítico. A vida para a Psicanálise é a vida humana; ela sofre as interferências do símbolo desde onde se conjuga com a morte.

\section{VIDA E SEXUALIDADE EM HANNAH ARENDT E NA PSICANÁLISE}

Colocando frente a frente o que se definiu como eixos para abordar o conceito de vida em Hannah Arendt e na Psicanálise, entende-se que ambas as análises não são essencialmente convergentes, embora apontem para um ponto comum: o imperativo da felicidade vigente na época atual, sendo esta uma experiência de satisfação ligada ao corpo. Quanto à não convergência das análises, destacam-se dois pontos. Primeiro, se para Hannah Arendt a vida é natural, para a Psicanálise, ela é irreversivelmente marcada pelo símbolo. Segundo a concepção arendtiana, corpo, sexualidade, vida e necessidade se referem à natureza, constituindo o que o homem tem em comum com os animais. Já para a Psicanálise, há um hiato entre o âmbito humano e o natural, pois a linguagem subverte as funções da biologia. A rigor, homens e animais não compartilham nenhuma natureza. Ainda que ambos se comuniquem, reproduzam-se, vivam, tenham corpos e necessidades biológicas, cada uma dessas funções responde a um regime diverso, conforme se refira a homens ou a animais. Quanto ao segundo aspecto, ou seja, o fato de Hannah Arendt pensar a vida a partir de um paradigma positivo com base em noções como produção, fertilidade, abundância e processo, observa-se que a divergência da Psicanálise em relação a esse referencial ocorre na medida em que esta última liga a vida à morte, trazendo para sua análise as marcas da perturbação, da desadaptação e da divisão do sujeito que habita um corpo.

Entende-se que as diferenças apontadas quanto às noções de vida e sexualidade nas obras de Freud, Lacan e Hannah Arendt designam posicionamentos fundamentais desses autores. Arendt dedica-se a uma crítica da sociedade moderna, fazendo-se tributária da divisão entre natureza e política de Aristóteles, com vistas 
a iluminar o que falta em um tempo marcado pela intimidade solipsista. E, ainda que suas propostas inspirem ações afirmativas no contexto político corrente, seu pensamento sofre de uma separação artificial entre vida e política, advogando a exclusão das questões ligadas à administração das necessidades da atividade

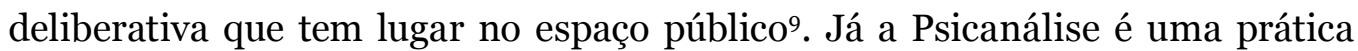
constituída a partir da escuta de sujeitos inseridos no regime da intimidade e dá testemunho da relação intrínseca entre o símbolo e os dados da biologia no homem. A novidade que a Psicanálise trouxe em relação à sexualidade foi exatamente a subversão de seu caráter natural, a noção de que o sexo não é um fato do instinto, mas da pulsão, de que o corpo sofre da linguagem, além de gozar dela. Isso implica que, ainda que o homem socializado não tenha como experiência privilegiada a liberdade na esfera pública, ele não pode ser reduzido à animalidade; a linguagem está irremediavelmente imiscuída em suas entranhas.

\section{REFERÊNCIAS BIBLIOGRÁFICAS:}

ARENDT, Hannah. O que é liberdade? In: ARENDT, Hannah. Entre o passado e o futuro. São Paulo: Perspectiva, 2009.

A condição humana. Rio de Janeiro: Forense Universitária, $2010 a$.

. A vida do espírito: o pensar, o querer, o julgar. Rio de Janeiro: Civilização Brasileira, 2010b.

Totalitarian imperialism: reflections on Hungarian revolution. The journal of politics. v. 20, n. 1, p. 5-43, Feb. 1958. Disponível em: <http://www.jstor.org/ stable/2127387>. Acesso em: 30 jun. 2010c.

. Sobre a revolução. São Paulo: Companhia das Letras, 2011.

BenHABib, Seyla. Models of public space: Hannah Arendt, the liberal tradition, and Jürgen

Habermas. In: CRAIG, Calhon (Org.). Habermas and the public sphere. Cambridge, Mass.: MIT Press, 1992. p. 73-98.

Blencowe, Claire. Foucault's and Arendt's "insider view" of biopolitics: a critique of Agamben. History of Human Sciences, v. 23, n. 5, p. 113-130, 2010. Disponível em: $<$ http://hhs.sagepub.com/content/23/5/113>. Acesso em: 24 jan. 2013. Foucault, Michel. Em defesa da sociedade. São Paulo: Ed. Martins Fontes, 1999.

9 Sobre uma crítica à predefinicão do que pertence aos âmbitos público e privado feita por Arendt, ver a noção de "essencialismo fenomenológico", em Benhabib (1992, p. 80). 
FreUd, Sigmund. A concepção psicanalítica da perturbação psicogênica da visão. In: FreUd, Sigmund. Edição standard das obras psicológicas completas de Sigmund Freud. Rio de Janeiro: Imago, 1976. v. XI. p. 193-203.

. À guisa de introdução ao narcisismo. In: Freud, Sigmund. Obras psicológicas de Sigmund Freud - escritos sobre a psicologia do inconsciente. Rio de Janeiro: Imago, 2004. v. II. p. 95-131.

. A interpretação dos sonhos. In: Freud, Sigmund. Edição standard das obras psicológicas completas de Sigmund Freud. Rio de Janeiro: Imago, 1987. vol. IV e V. Além do princípio de prazer. In: FREUD, Sigmund. Obras psicológicas de Sigmund Freud - escritos sobre a psicologia do inconsciente. Tradução de Luiz Alberto Hanns. Rio de Janeiro: Imago, 2006a. v. II. p. 123-198.

Pulsões e destinos da pulsão. In: FreUd, Sigmund. Obras psicológicas de Sigmund Freud - escritos sobre a psicologia do inconsciente. Tradução de Luiz Alberto Hanns. Rio de Janeiro: Imago, 2006b. v. II. p. 133-173.

. Três ensaios sobre a teoria da sexualidade. In: Freud, Sigmund. Edição standard das obras psicológicas completas de Sigmund Freud. Rio de Janeiro: Imago, 1972. p. 123-250. v. VII.

GARSPAR, Ronaldo. Hannah Arendt: sobre Karl Marx e a revolução. Lutas sociais. São Paulo, n. 27, p. 58-68. 2 sem. 2011.

Kristeva, Julia. Hannah Arendt. New York: Columbia Press University, 2001.

LACAN, Jacques. O seminário, livro 2: o eu na teoria de Freud e na técnica da psicanálise. Rio de Janeiro: Jorge Zahar Editor, 1985.

. Posição do inconsciente. In: LacAn, Jacques. Escritos. Rio de Janeiro: Jorge Zahar Editor, 1998. p. 843-864.

O seminário, livro 20: mais, ainda. Rio de Janeiro: Jorge Zahar Editor, 2008. O seminário, livro 1: os escritos técnicos de Freud. Rio de Janeiro: Jorge Zahar Editor, 2009.

Miller, Jacques-Alain. Biologia lacaniana e acontecimentos de corpo. Opção lacaniana, São Paulo, n. 41, p. 7-67, 2004.

Wellmer, Albrecht. Arendt on revolution. In: Villa, Dana (Org.). The Cambridge Companion to Hannah Arendt. New York: Cambridge University Press, 2002. p. 220-241.

Recebido para publicação em 08/05/2013. Aceito para publicação em 12/11/2013. 